\title{
In Silico Prediction of Interactions between Site II on Human Serum Albumin and Profen Drugs
}

\author{
Hideto Isogai and Noriaki Hirayama \\ Basic Medical Science and Molecular Medicine, Tokai University School of Medicine, 143 Shimokasuya, Isehara, \\ Kanagawa 259-1193, Japan \\ Correspondence should be addressed to Noriaki Hirayama; hirayama@is.icc.u-tokai.ac.jp
}

Received 21 January 2013; Accepted 6 February 2013

Academic Editors: R. A. Caceres, A. Ghosal, and H. Sah

Copyright (C) 2013 H. Isogai and N. Hirayama. This is an open access article distributed under the Creative Commons Attribution License, which permits unrestricted use, distribution, and reproduction in any medium, provided the original work is properly cited.

\begin{abstract}
Since binding of a drug molecule to human serum albumin (HSA) significantly affects the pharmacokinetics of the drug, it is highly desirable to predict the binding affinity of the drug. Profen drugs are a widely used class of nonsteroidal anti-inflammatory drugs and it has been reported that several members of the profen class specifically bind to one of the main binding sites named site II. The actual binding mode of only ibuprofen has been directly confirmed by X-ray crystallography. Therefore, it is of interest whether other profen drugs are site II binders. Docking simulations using multiple template structures of HSA from three crystal structures of complexes between drugs and HSA have demonstrated that most of the currently available profen drugs should be site II binders.
\end{abstract}

\section{Introduction}

Human serum albumin (HSA) which is the most abundant plasma protein binds vast array of chemically diverse exogenous and endogenous molecules [1]. Binding of a drug molecule to HSA results in increased solubility in plasma, decreased toxicity, and protection against oxidation of the bound molecule. Since HSA binding is one of the important factors which determine the ADME properties of the drugs, it is highly desirable to know the binding affinity of drugs in order to avoid undesirable drug-drug interactions. There are two approaches to predict protein-ligand interactions. Ligand-based approaches mostly use quantitative structureactivity relationships (QSARs) which are based on chemical structures and physicochemical properties of a series of compounds whose HSA binding affinities have been measured [2]. High-resolution crystal structures of HSA complexed with various molecules have shown that there are two main binding sites named sites I and II [3]. As site I is large and flexible multichamber, a variety of different molecules can bind to site I. On the contrary, ligands binding to site II are usually aromatic carboxylic acids with a negative charged group at one end of the molecule away from a hydrophobic center. Based on the reliable crystal structures, structurebased approaches are possible. The molecular docking methods, in particular, which have been largely improved recently can be applied to predict the interaction modes of drugs and the binding sites in atomic detail comparable to the experimental results.

Since nonsteroidal anti-inflammatory drugs (NSAIDs) are among the most commonly used medications [4], the drug-drug interactions involving NSAIDs are important issues in many drug discovery projects. In particular, 2-aryl propionic acids (profen drugs) are a widely used class of NSAIDs and represent a significant share of the pharmaceutical market. In Figure 1(a), chemical structures of eleven typical profens are shown. The binding modes of flurbiprofen [5], ibuprofen [3], ketoprofen [6], naproxen [7], pranoprofen [8], and suprofen [9] have been experimentally suggested so far, albeit the exact binding mode of ibuprofen only was confirmed by X-ray crystallography. The binding site of these six profen drugs is reported to be site II. It is particularly interesting to confirm whether all of the eleven profen drugs including ibuprofen bind to site II. Therefore, in this study we have predicted whether these profen drugs can actually bind to site II by docking simulations. 
The results have shown that docking simulations can satisfactorily predict the binding of site-II-specific drugs to site II. The docking simulations undertaken in a similar way have demonstrated that all of the profen drugs shown in Figure 1(a) can bind to site II.

\section{Methods}

2.1. Docking Simulations. All docking simulations were undertaken by use of software ASEDock [10]. ASEDock is based on unique concept of ASE model and ASE score. Since ASEDock is free from any bias except for shape, it is a very robust docking method. During refinement, backbone atoms of the HSA molecules were fixed and the positions of all other atoms were optimized. Docking results were evaluated by an efficiency index defined as follow:

$$
\mathrm{EI}_{U_{\text {dock }}}=\frac{U_{\text {dock }}}{\mathrm{HA}}
$$

where HA denotes the number of nonhydrogen atoms in a ligand and $U_{\text {dock }}=U_{\text {ele }}+U_{\mathrm{vdw}}+U_{\text {strain }}$. Here, $U_{\text {ele }}$ and $U_{\mathrm{vdw}}$ mean electrostatic and van der Waals interaction energies, respectively, between HSA and ligand molecules. $U_{\text {strain }}$ refers to the difference between the conformation energy of a docked ligand and that of the minimum energy conformation nearest to the docked-ligand structure. EI_U dock corresponds to ligand efficiency [11]. The interaction between biotin and streptavidin is one of the strong noncovalent interactions known in nature [12]. The experimentally determined interaction energy per nonhydrogen atom is $-1.6 \mathrm{kcal} /(\mathrm{mol} \cdot \mathrm{HA})$ [13]. Based on this value, the threshold value of EI_U $U_{\text {dock }}$ to judge site II binders was arbitrarily set to be $-1.5 \mathrm{kcal} /$ (mol.HA) in this study.

A software system MOE (Molecular Operating Environment) [14] was used throughout this study. All the calculations were performed on a DELL PC workstation T7500 equipped with two Intel Xeon X5690 processors and 128 GB memory.

2.2. Selection of Docking Templates. Selection of suitable template crystal structures is essential for docking simulations. When we started our study, six crystal structures of complexes between HSA and different drug molecules were available. The PDB (Protein Data Bank [15]) codes are 1E7A (2.20, 0.248), 2BXA (2.35, 0.230), 2BXE (2.95, 0.226), 2BXF $(2.95,0.215), 2 \mathrm{BXG}(2.70,0.234)$, and 2BXH $(2.25,0.227)$. The two numbers in the parentheses denote the resolution and the $R$ factor, respectively. Since these six drug molecules are relatively variable in chemical structure as shown in Figure 1(b), the crystal structures reveal descent induced-fit effect around drug-binding sites. In this study, consensusbased approach was taken in order to consider the induced-fit effect by using multiple templates for docking simulations.

Redocking simulations for these six structures have been undertaken for the validation of the algorithm of ASEDock against the HSA-drug system. Docking accuracy is usually measured by the root-mean-square deviation (rmsd) of nonhydrogen atom positions in the predicted ligand structure versus those in the crystal structure. The rmsd values $(\AA)$ obtained by redocking are $0.28,0.70,0.46,0.31,0.95$, and 0.58 for 1E7A, 2BXA, 1BXE, 2BXF, 2BXG, and 2BXH, respectively. Since prediction within rmsd of $2.0 \AA$ is held as the passing standard, the results indicate that ASEDock is suitable for the HSA-drug system.

In this study, three template crystal structures of 1E7A, 2BXA, and 1BXE which gave the smallest rmsds in the redocking simulations were selected as template structures. As the largest and the smallest drugs in size are bound to the HSA molecule in these structures, the consensus analysis using these structures as templates is expected to take the induced-fit effect into account to some extent and should be applicable to docking simulations between HSA and a variety of different molecules.

2.3. Selection of Compounds for Evaluation. Since our purpose is to predict compounds which likely bind to site II, we must evaluate whether docking simulations can distinguish site II binders from other compounds. For this evaluation, we prepared three sets of compounds. The first set of 1,444 compounds mainly consists of drug molecules clinically applied in Japan now. The active metabolites of the drugs which have been reported in the literatures are also included in this dataset (DS1). Six drug molecules complexed with HSA in the crystal structures and nine additional compounds (Figure 1(c)) whose binding to site II was experimentally confirmed by NMR [16] were included in the second dataset of DS2. The compounds in DS2, 15 in total, are positive controls whose binding sites have been confirmed by X-ray crystallography or NMR. The third dataset (DS3) consists of eleven profen drugs. The binding of only ibuprofen to site II has been crystallographically confirmed. All the compounds in DS2 and DS3 are included in DS1.

\section{Results and Discussion}

The docking simulations between three HSA template structures and all molecules in DS1 have been undertaken. The docking results were sorted in descending order of EI $U_{\text {dock }}$. The docked structure with the lowest EI_U dock value for each molecule was selected. The enrichment curve of the site II binders in DS2 is illustrated in Figure 2. The enrichment rate at the $-1.5 \mathrm{kcal} /(\mathrm{mol} \cdot \mathrm{HA})$ cut is 5.67 . The rapid enrichment indicates that EI_ $U_{\text {dock }}$ is a reasonable criterion to judge the site II binders. 13 drugs out of 15 site II binders were included in 221 compounds whose EI_ $U_{\text {dock }}$ is lesser than $-1.5 \mathrm{kcal} /(\mathrm{mol} \cdot \mathrm{HA})$. The EI_U dock values for indomethacin and clotrimazole were -1.09 and $-0.64 \mathrm{kcal} /(\mathrm{mol} \cdot \mathrm{HA})$, respectively, and they were not judged to be site II binders by the current threshold value of EI $U_{\text {dock }}$. Indomethacin is regarded as a site I binder in a recently published paper [17]. Clotrimazole is relatively bulkier than other 13 drug molecules and it might well be that the molecule cannot be properly accommodated at site II in the three template structures used in this study. However, from the practical point of view, the enrichment rate of 5.67 seems to be good enough to judge the site II binders. It is likely 

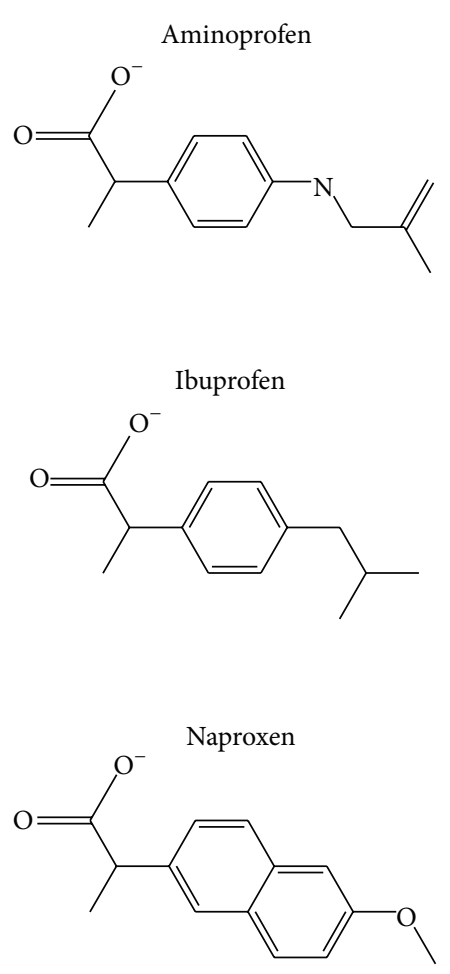<smiles>CC(C(=O)[O-])c1ccc(C(=O)c2ccccc2)s1</smiles>

PFL (propofol): 1E7A<smiles>CC(C)c1cccc(C(C)C)c1O</smiles>

DZP (diazepam): 2BXF1

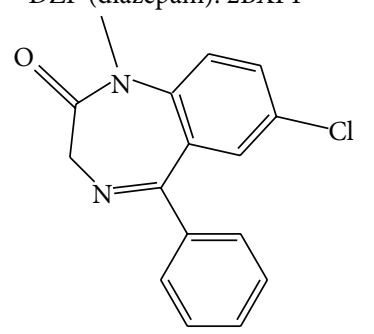

Fenoprofen

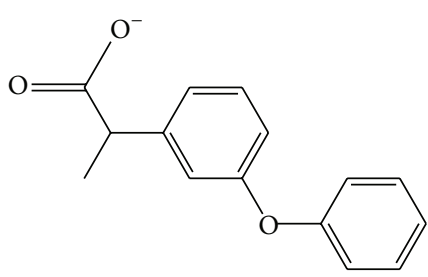

Ketoprofen

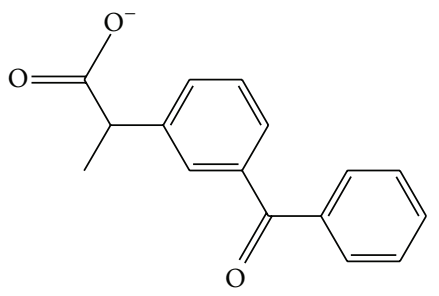

Pranoprofen

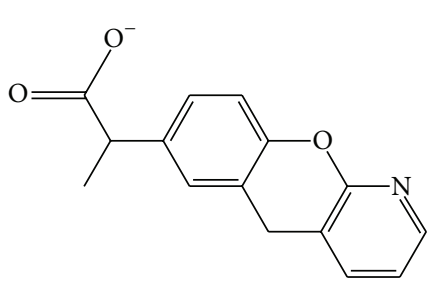

Zaltoprofen

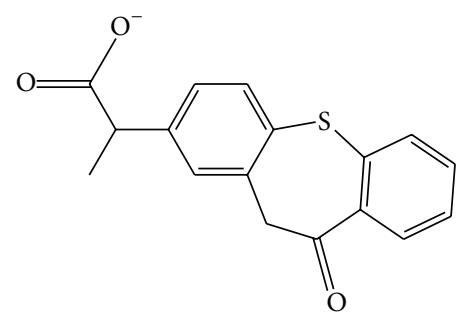

(a) Chemical structures of 11 profen class drugs

C1F (3-carboxy-4-methyl-5-propyl-2furanpropionic acid): $2 \mathrm{BXA}$

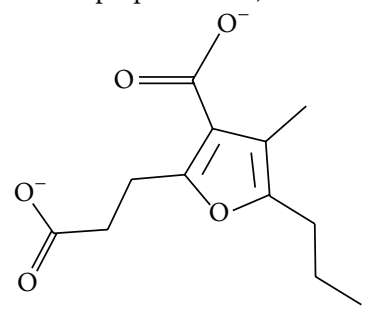

IBP (ibuprofen): 2BXG

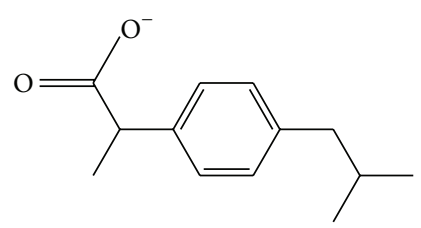

Flurbiprofen

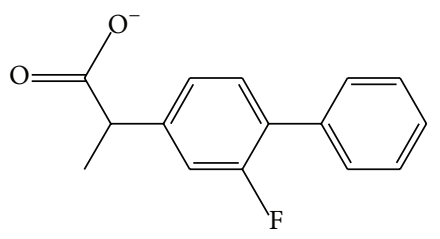

Loxoprofen

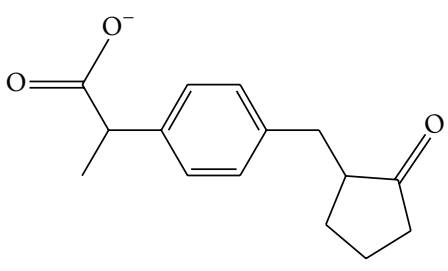

Suprofen

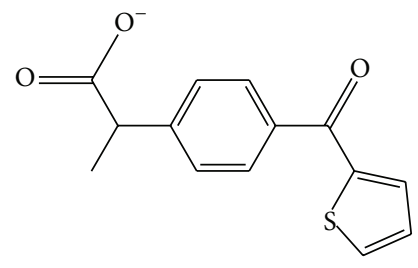

(b) Chemical structures of ligands whose complexes with HSA were determined by X-ray analysis

FIGURE 1: Continued. 


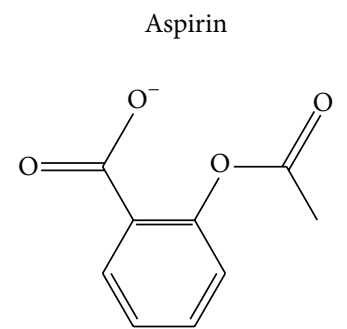

Clotrimazole

Chlorpropamide

Clofibrate<smiles>CCOC(=O)COc1ccc(Cl)cc1</smiles>

Ketoprofen<smiles>Clc1ccccc1C(c1ccccc1)(c1ccccc1)n1ccnc1</smiles>

Naproxen

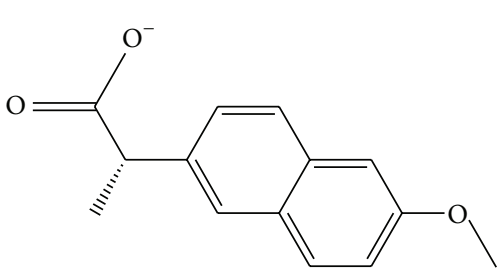

Indomethacin<smiles>COc1ccc2c(c1)c(CC(=O)[O-])c(C)n2C(=O)c1ccc(Cl)cc1</smiles>

Salicylic acid

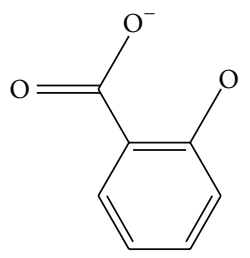

Tolbutamide<smiles>CC(C(=O)[O-])c1cccc(C(=O)c2ccccc2)c1</smiles>

(c) Chemical structures of ligands whose site II binding affinities were measured and confirmed by NMR

Xinafoate<smiles>O=C([O-])c1ccc2ccccc2c1O</smiles>

Valproic acid
Nabumetone

$\mathrm{O}$

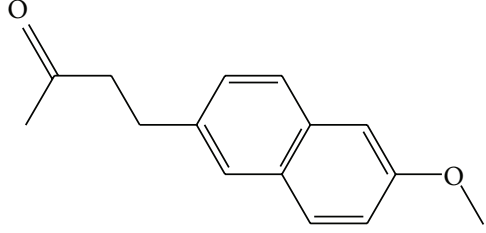

6MNA<smiles>CCCC(CCC)C(=O)O</smiles>

(d) Chemical structure of other molecules

FIGURE 1: Chemical structures of drug molecules.

that some drugs in the remaining 208 drugs are site II binders. Therefore, the actual enrichment rate is expected to be higher than 5.67. The present study has clearly indicated that by use of the EI_ $U_{\text {dock }}$ values we can distinguish site II binders in a set of compounds.
The EI_U dock values of eleven profen drugs are given in Table 1. The EI_U dock values of 10 profens are less than $-1.5 \mathrm{kcal} /(\mathrm{mol} \cdot \mathrm{HA})$ and those drugs are considered to be strong site II binders. The exception is zaltoprofen and the EI $U_{\text {dock }}$ value is $-1.40 \mathrm{kcal} /(\mathrm{mol} \cdot \mathrm{HA})$. If all these eleven 


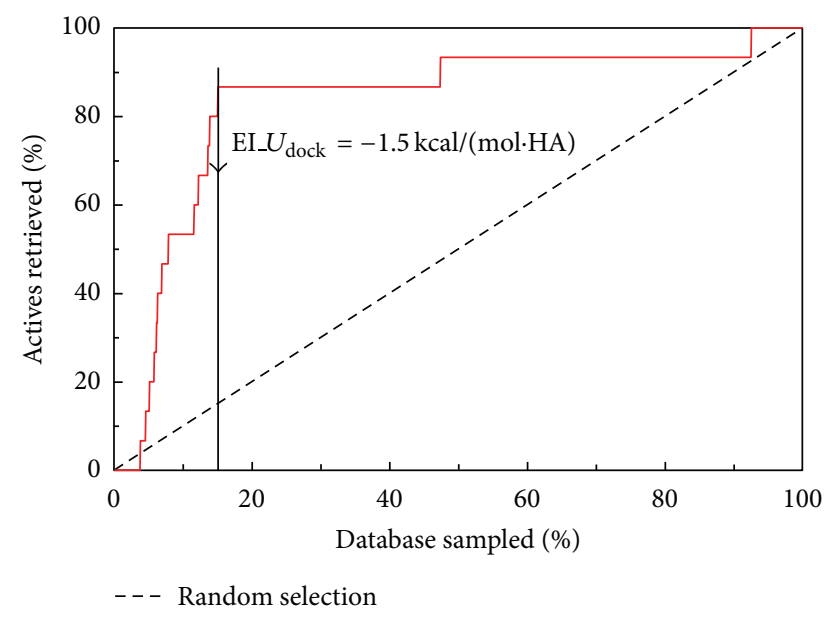

FIGURE 2: Enrichment curve for 15 site II binders. Solid line shows the predicted result.

TABLE 1: The EI_U dock values of the intermolecular interactions between profen drugs and HAS.

\begin{tabular}{lcc}
\hline Profens & $\mathrm{EI}_{-} U_{\text {dock }}(\mathrm{kcal} /(\mathrm{mol} \cdot \mathrm{HA}))^{1}$ & PDB ID \\
\hline Ibuprofen & -1.92 & $1 \mathrm{E} 7 \mathrm{~A}$ \\
Naproxen & -1.89 & $1 \mathrm{E} 7 \mathrm{~A}$ \\
Aminoprofen & -1.79 & $1 \mathrm{E} 7 \mathrm{~A}$ \\
Suprofen & -1.67 & $1 \mathrm{E} 7 \mathrm{~A}$ \\
Flurbiprofen & -1.63 & $1 \mathrm{E} 7 \mathrm{~A}$ \\
Fenoprofen & -1.61 & $1 \mathrm{E} 7 \mathrm{~A}$ \\
Tiaprofenic acid & -1.59 & $1 \mathrm{E} 7 \mathrm{~A}$ \\
Pranoprofen & -1.59 & $1 \mathrm{E} 7 \mathrm{~A}$ \\
Loxoprofen & -1.53 & $1 \mathrm{E} 7 \mathrm{~A}$ \\
Ketoprofen & -1.53 & $1 \mathrm{E} 7 \mathrm{~A}$ \\
Zaltoprofen & -1.40 & 2BXF \\
\hline
\end{tabular}

${ }^{1} \mathrm{HA}$ means the number of nonhydrogen atoms in a molecule.

profen drugs are site II binders, the enrichment rate at the $-1.5 \mathrm{kcal} /(\mathrm{mol} \cdot \mathrm{HA})$ cut is 5.48 . The binding mode of ibuprofen at site II disclosed by X-ray analysis (PDB ID: 2BXG) is illustrated in Figure 3(a). Three amino acid residues, Arg410, Tyr411, and Lys414, specifically cluster around ibuprofen. The oxygen atoms of the carboxylic acid of ibuprofen are hydrogen-bonded to the side chains of Arg410 and Tyr411. Suprofen is reported to be a site II binder [18], but the binding mode has not been confirmed spectroscopically or crystallographically. The EI_U dock value of $-1.67 \mathrm{kcal} /(\mathrm{mol} \cdot \mathrm{HA})$ indicates that suprofen would bind to site II. The binding mode of suprofen at site II is shown in Figure 3(b). This binding mode also implies that suprofen can bind to site II. The binding site of loxoprofen has not been identified experimentally. The EI_ $U_{\text {dock }}$ value of $-1.53 \mathrm{kcal} /(\mathrm{mol} \cdot \mathrm{HA})$ suggests that loxoprofen may bind to site II. The docking mode at site II shown in Figure 3(c) is very similar to that of ibuprofen. Therefore, loxoprofen should bind to site II. Other profens except zaltoprofen bind to site II in a similar manner. The binding affinity of zaltoprofen to site II is not comparable to those of other profen drugs, and its binding site has not been experimentally suggested so far. The binding mode of zaltoprofen is shown in Figure 3(d). The carboxyl oxygen atoms are hydrogen-bonded to Tyr 411 and Lys 414 instead of Arg410. It seems that zaltoprofen must shift marginally at site II in order to fit the bulky three-ring system to the site. As a result, Lys414 instead of Arg410 plays the role as a hydrogen-bond donor to the carboxyl oxygen atom of the drug molecule now. The binding mode clearly indicates that zaltoprofen should bind to site II. In summary, judging from the EI_U $U_{\text {dock }}$ values and docking modes obtained by docking simulations, all of the profen molecules shown in Figure 1(a) are considered to be site II binders.

A few noteworthy results have also been obtained. As the EI_ $U_{\text {dock }}$ value of nabumetone (Figure $1(\mathrm{~d})$ ) is $-1.45 \mathrm{kcal} /(\mathrm{mol} \cdot \mathrm{HA})$, nabumetone is not judged to be a strong site II binder. However, 6MNA (Figure 1(d)) is an active metabolite of nabumetone, and its EI_ $U_{\text {dock }}$ value is $-1.92 \mathrm{kcal} /(\mathrm{mol} \cdot \mathrm{HA})$. It suggests that not nabumetone itself but its metabolite can compete with other site II binders. In Figure 4(a), the binding mode of 6MNA at site II is shown. The specific interactions between the drug metabolite and Arg410 and Tyr411 are observed. The HSA binding affinity of xinafoate (Figure 1(d)) has not been reported so far. However, the EI_U $U_{\text {dock }}$ value of $-2.07 \mathrm{kcal} /(\mathrm{mol} \cdot \mathrm{HA})$ and the binding mode shown in Figure 4(b) suggest the possible binding affinity of xinafoate to site II. Since xinafoate is not an active ingredient and is used as a counterion of the principal agent such as salmeterol, it might be possible that its binding affinity has been unnoticed so far. An anticonvulsant valproic acid (Figure 1(d)) which is normally used as the sodium salt was reported to be a site I binder [19]. Our work, however, has indicated that valproic acid can bind to site II, too. In Figure 4(c), the binding mode of valproic acid at site II is shown. Judging from this binding mode and the small size, it is highly expected that valproic acid binds to site II. The above results have clearly indicated that the docking simulation method employed in this study is appropriate in predicting the affinity between site II and drug molecules.

\section{Conclusions}

Since the binding of a drug to HSA is crucial for its efficacy and toxicity, evaluation of the HSA binding affinity of the drug is a particularly important issue in pharmaceutical research. The experimental measurements are timeconsuming and require a lot of resources. In addition, especially in the early stage of drug discovery projects, it is highly required to synthesize compounds with appropriate binding affinity to HSA in order to avoid the future problems. In this study we have demonstrated that docking simulation can satisfactorily predict the binding of site-II-specific drugs to site II. The docking simulations have indicated that profen drugs whose binding modes have not been experimentally 


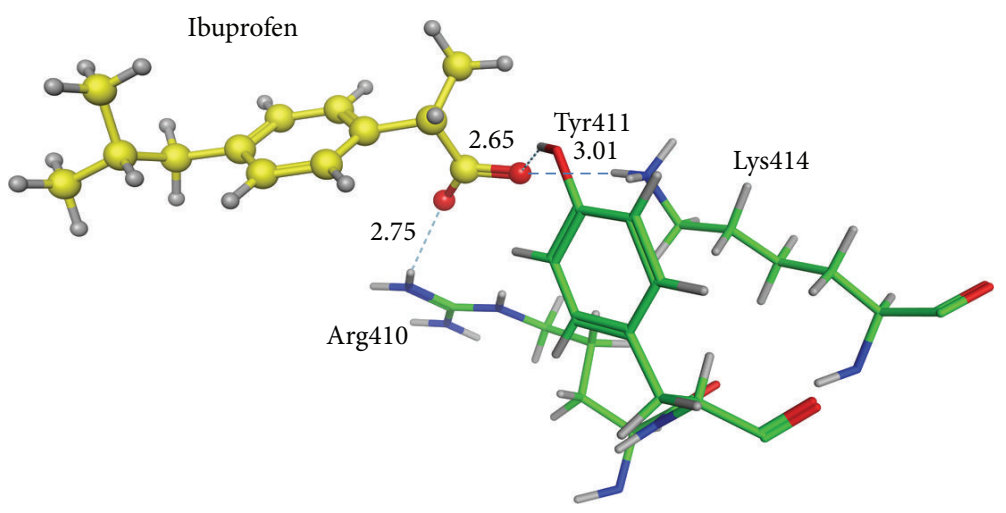

(a) Ibuprofen in the crystal structure of 2BXG

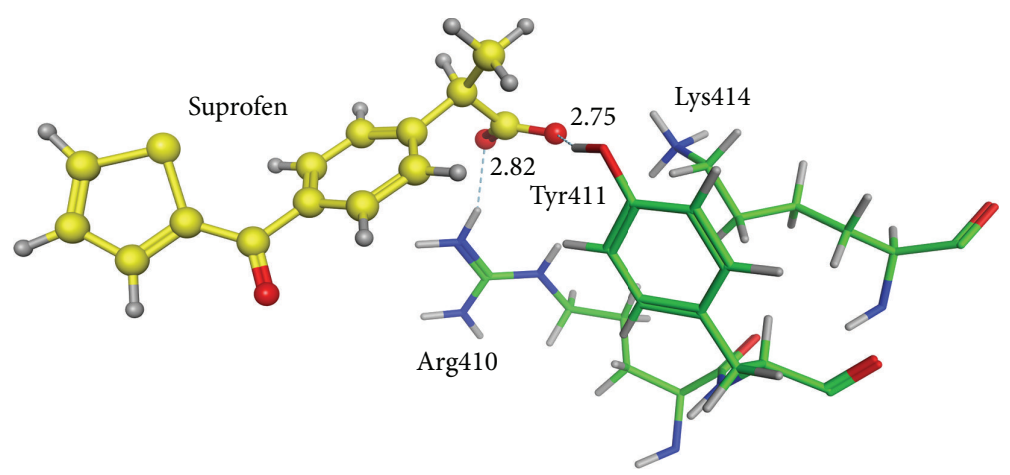

(b) Suprofen

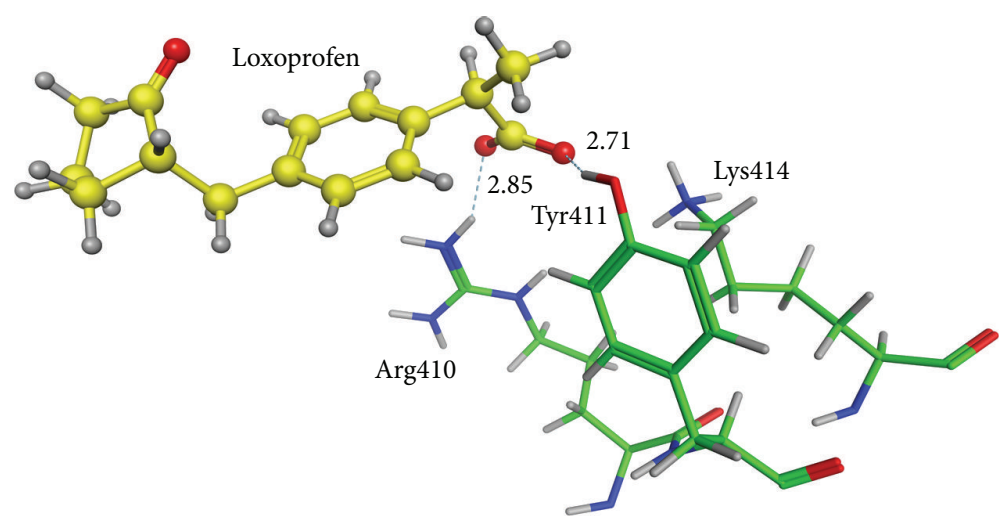

(c) Loxoprofen

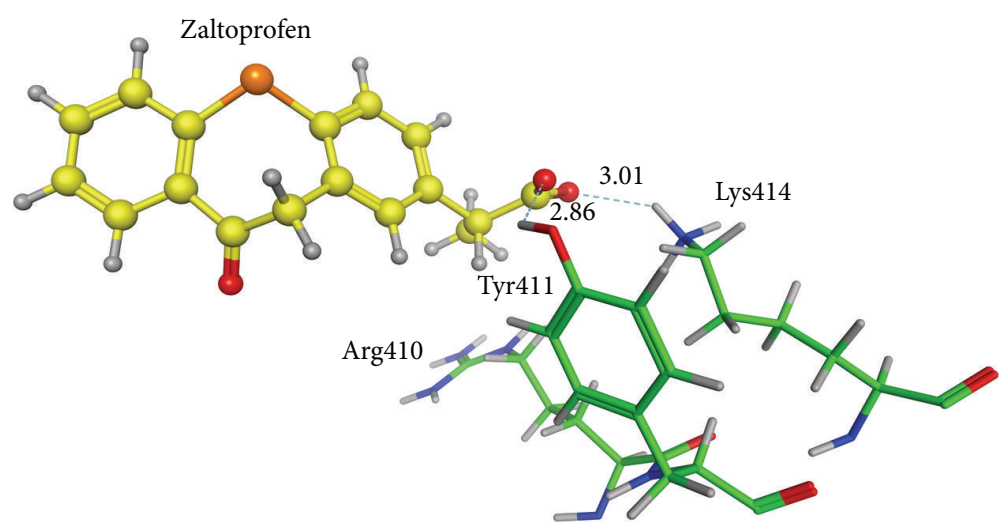

(d) Zaltoprofen

FIgURE 3: Binding modes of profens at site II. Dotted lines show hydrogen bonds with the hydrogen bond distances $(\AA)$. 


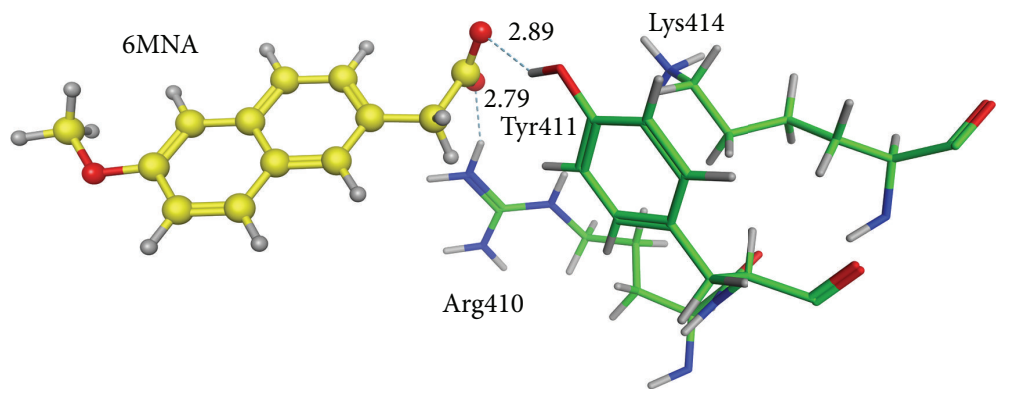

(a) 6MNA

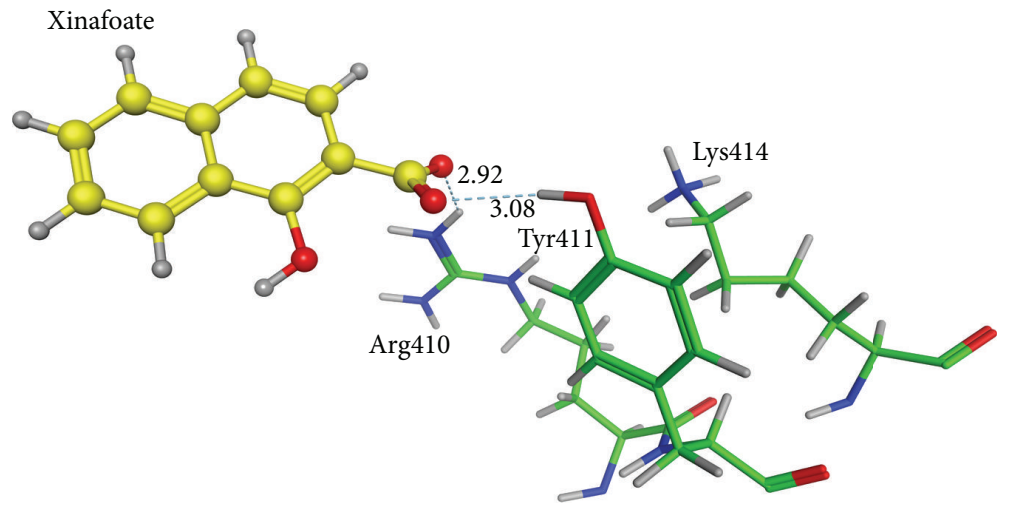

(b) Xinafoate

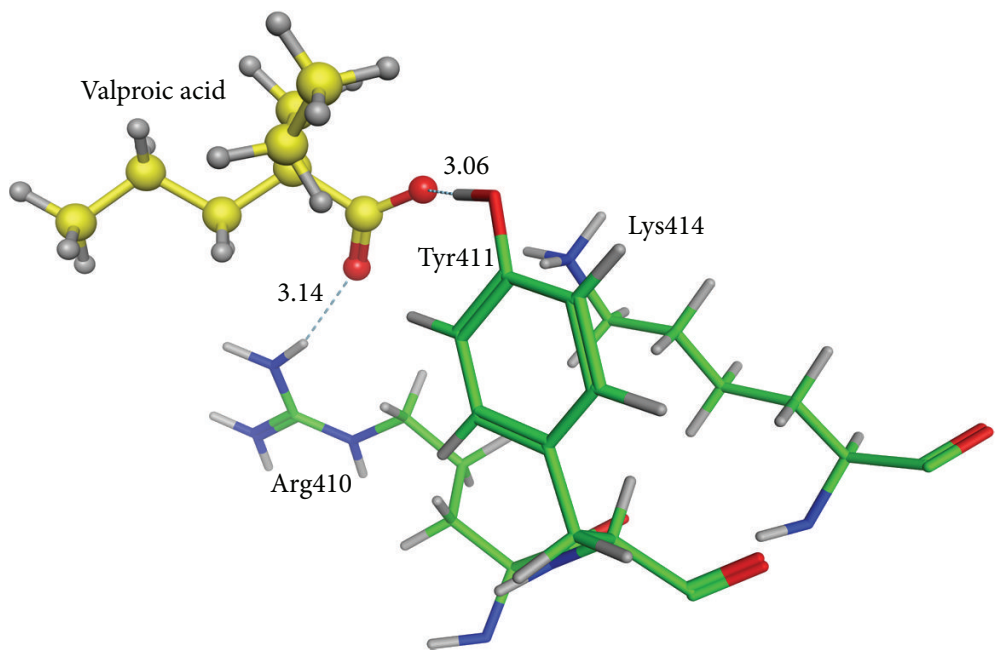

(c) Valproic acid

FIGURE 4: Binding modes of some other ligands of interest at site II. Dotted lines show hydrogen bonds with the hydrogen bond distances ( $)$.

determined would bind to site II. Although docking simulation is a highly CPU-intensive job, the CPU time normally required is becoming not a serious problem and it can substantially substitute experimental measurements now.

\section{Acknowledgments}

This work was partly supported by Grant-in-Aid for Scientific Research (A) (19200024) from MEXT (Ministry of Education, Culture, Sports, Science and Technology) for N. Hirayama.

\section{References}

[1] S. Curry, "Lessons from the crystallographic analysis of small molecule binding to human serum albumin," Drug Metabolism and Pharmacokinetics, vol. 24, no. 4, pp. 342-357, 2009.

[2] G. Sudlow, D. J. Birkett, and D. N. Wade, "The characterization of two specific drug binding sites on human serum albumin," Molecular Pharmacology, vol. 11, no. 6, pp. 824-832, 1975.

[3] J. Ghuman, P. A. Zunszain, I. Petitpas, A. A. Bhattacharya, M. Otagiri, and S. Curry, "Structural basis of the drug-binding specificity of human serum albumin," Journal of Molecular Biology, vol. 353, no. 1, pp. 38-52, 2005. 
[4] J. P. Curtis and H. M. Krumholz, "The case for an adverse interaction between aspirin and non-steroidal anti-inflammatory drugs: is it time to believe the hype?" Journal of the American College of Cardiology, vol. 43, no. 6, pp. 991-993, 2004.

[5] B. Honoré and R. Brodersen, "Albumin binding of anti-inflammatory drugs. Utility of site-oriented versus a stoichiometric analysis," Molecular Pharmacology, vol. 25, no. 1, pp. 137-150, 1984.

[6] H. Watanabe, S. Tanase, K. Nakajou, T. Maruyama, U. KraghHansen, and M. Otagiri, "Role of Arg-410 and Tyr-411 in human serum albumin for ligand binding and esterase-like activity," Biochemical Journal, vol. 349, no. 3, pp. 813-819, 2000.

[7] I. Sjöholm, B. Ekman, A. Kober, I. Ljungstedt-Påhlman, B. Seiving, and T. Sjödin, "Binding of drugs to human serum albumin: XI. The specificity of three binding sites as studied with albumin immobilized in microparticles," Molecular Pharmacology, vol. 16, no. 3, pp. 767-777, 1979.

[8] T. Nomura, K. Sakamoto, T. Imai, and M. Otagiri, "Study of interaction of pranoprofen with human serum albumin: binding properties of enantiomers and metabolite," Journal of Pharmacobio-Dynamics, vol. 15, no. 10, pp. 589-596, 1992.

[9] T. Maruyama, C. C. Lin, K. Yamasaki et al., "Binding of suprofen to human serum albumin. Role of the suprofen carboxyl group," Biochemical Pharmacology, vol. 45, no. 5, pp. 1017-1026, 1993.

[10] J. Goto, R. Kataoka, H. Muta, and N. Hirayama, "ASEDockdocking based on alpha spheres and excluded volumes," Journal of Chemical Information and Modeling, vol. 48, no. 3, pp. 583590, 2008.

[11] I. D. Kuntz, K. Chen, K. A. Sharp, and P. A. Kollman, “The maximal affinity of ligands," Proceedings of the National Academy of Sciences of the United States of America, vol. 96, no. 18, pp. 999710002, 1999.

[12] N. M. Green, "Avidin," Advances in Protein Chemistry, vol. 29, no. 1, pp. 85-133, 1975.

[13] T. Lazaridis, A. Masunov, and F. Gandolfo, "Contributions to the binding free energy of ligands to avidin and streptavidin," Proteins, vol. 47, no. 2, pp. 194-208, 2002.

[14] MOE (Molecular Operating Environment), Chemical Computing Group, Montreal, Quebec, Canada, 2011.

[15] F. C. Bernstein, T. F. Koetzle, G. J. Williams et al., "The protein data bank: a computer based archival file for macromolecular structures," Journal of Molecular Biology, vol. 112, no. 3, pp. 535542, 1977.

[16] P. J. Hajduk, R. Mendoza, A. M. Petros et al., "Ligand binding to domain-3 of human serum albumin: a chemometric analysis," Journal of Computer-Aided Molecular Design, vol. 17, no. 2-4, pp. 93-102, 2003.

[17] F. Zsila, Z. Bikadi, D. Malik et al., "Evaluation of drug-human serum albumin binding interactions with support vector machine aided online automated docking," Bioinformatics, vol. 27, no. 13, Article ID btr284, pp. 1806-1813, 2011.

[18] N. A. Kratochwil, W. Huber, F. Müller, M. Kansy, and P. R. Gerber, "Predicting plasma protein binding of drugs: a new approach," Biochemical Pharmacology, vol. 64, no. 9, pp. 13551374, 2002.

[19] N. Takamura, S. Shinozawa, T. Maruyama, A. Suenaga, and M. Otagiri, "Effects of fatty acids on serum binding between furosemide and valproic acid," Biological and Pharmaceutical Bulletin, vol. 21, no. 2, pp. 174-176, 1998. 

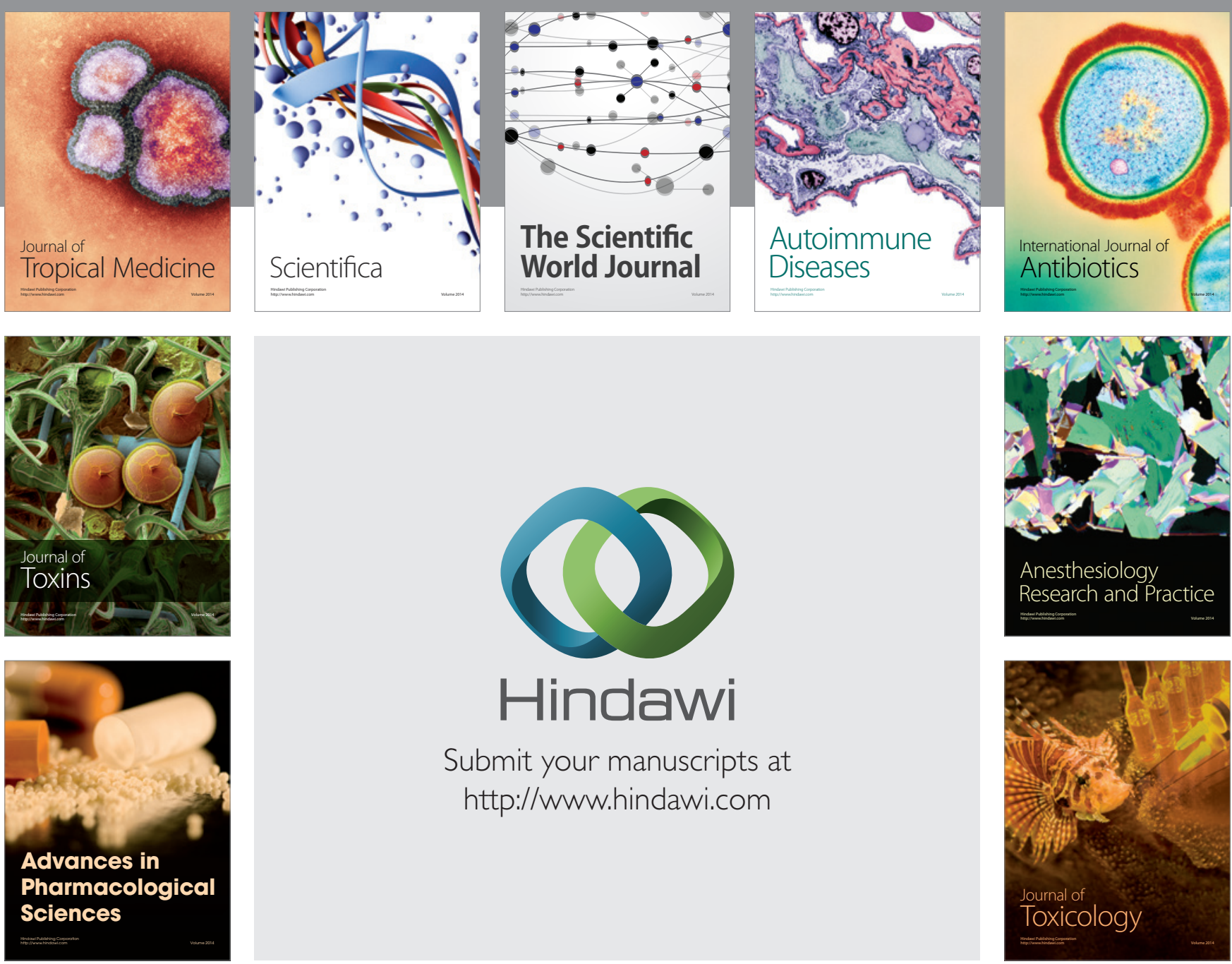

\section{Hindawi}

Submit your manuscripts at

http://www.hindawi.com
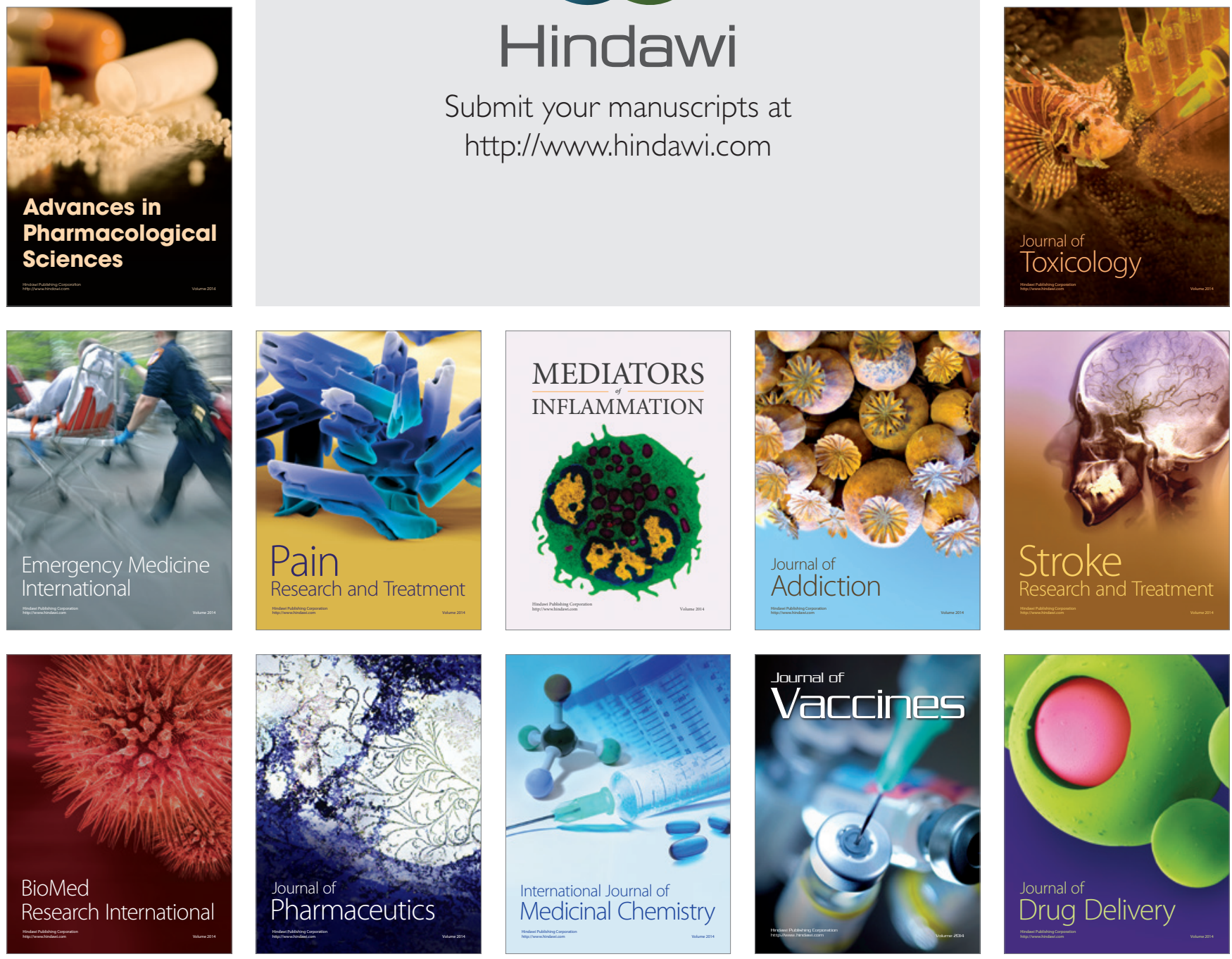